Scientiæ studia, São Paulo, v. 9, n. 1, p. 167-87, 2011

\title{
ist \\ Pragmática da investigação científica: uma abordagem nomológica
}

\author{
Luiz Henrique Dutra, Cezar Mortari, \\ Jerzy Brzozowski \& Thiagus Batista

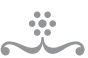

RESUMO

Este artigo procura discutir um dos episódios-tipo da atividade científica - a saber, a publicação de artigos científicos - do ponto de vista de uma análise da pragmática da investigação em convergência com a perspectiva de Patrick Suppes sobre o que seria uma escolha livre. Em primeiro lugar, é apresentada a ideia de Suppes de introduzir uma medida para a liberdade. Em seguida, oferece-se um esboço da noção de pragmática da investigação científica. Finalmente, introduz-se uma interpretação de uma trajetória de investigação em termos de cadeias de Markov.

Palavras-chave • Pragmática da investigação. Cadeias de Markov. Escolha livre. Artigos científicos.

Patrick Suppes.

Tradicionalmente, a atividade científica é tomada como paradigma da ação racional, atividade na qual o pensamento humano livre de quaisquer restrições pode avaliar o valor das ideias e escolher livremente entre elas com base em argumentos logicamente válidos. A perspectiva defendida neste artigo não vai contra essa noção, nem contra a concepção mais geral segundo a qual o comportamento racional consiste em pesar prós e contras um curso de ação e, com base em tais razões, agir. Assim como Suppes, apenas procuramos compreender esse tipo de comportamento como o resultado de determinados contextos.

No caso da atividade científica especificamente, há contextos científicos institucionalizados que devem ser compreendidos para que possamos perceber em que medida é possível falar de escolhas livres e racionais da parte do cientista quando se ocupa de teorias, evidências, testes, aplicações etc., inclusive a divulgação de resultados alcançados. Este último ponto, no caso da publicação de artigos científicos, é o foco da análise que vamos apresentar.

Outra concepção tradicional que poderia impedir de adotar tal abordagem para compreender a ciência é aquela segundo a qual a filosofia da ciência não deveria se ocupar da prática científica concreta, mas apenas da legitimidade e racionalidade de 
seus produtos mais altos - as teorias científicas. Trata-se da separação entre os contextos de descoberta e justificação, perspectiva defendida por diversos autores e escolas epistemológicas, entre elas o positivismo lógico e o racionalismo crítico (de Popper). Esta concepção já está de longa data desafiada por abordagens de tendência naturalista na epistemologia, que remonta a Quine (1969), entre elas, em especial, a de Kuhn (1996). O termo 'naturalismo' aqui se refere à ideia geral de tomar em consideração também a prática científica e a história das ciências, e de não manter de maneira rígida a separação entre os contextos de descoberta e de justificação.

Assim, a abordagem esboçada neste artigo adota também essa perspectiva naturalista moderada, que se traduz na possibilidade sempre aberta de tomar uma análise de como se dão as coisas nas investigações científicas reais, na prática dos cientistas profissionais, como ponto de partida das reflexões a serem feitas sobre os grandes temas da filosofia da ciência. As linhas gerais da abordagem que esboçamos aqui para a análise da atividade de publicação de artigos científicos é uma das formas concretas de colocar em prática tal perspectiva.

Na primeira das seções abaixo, discutimos as ideias de Suppes sobre uma possível medida para a liberdade. Na seção 2, apresentamos algumas das noções centrais ligadas à análise da pragmática da investigação científica que complementam a fundamentação dessa perspectiva. Na seção 3, esboçamos a estratégia metodológica que viabilizaria a aplicação de tais ideias à análise de trajetórias de investigação por meio da publicação de artigos científicos.

\section{Suppes e A Ideia De uma medida PARA A liberdade}

Patrick Suppes é um dos grandes defensores da concepção semântica das teorias científicas. Além disso, ele deu importantes contribuições para a fundamentação teórica da psicologia científica (cf., por exemplo, Suppes, 1985). Ele privilegiou a abordagem behaviorista em psicologia, embora tenha se distanciado do behaviorismo radical de Skinner, como ele conta em sua autobiografia intelectual. ${ }^{1}$ No artigo "Behavioristic foundations of utility" (1961), Suppes esboçou uma teoria behaviorista da utilidade, de teor similar àquela de Richard Herrnstein (1997). Neste artigo, adotamos o mesmo tipo de perspectiva behaviorista que Suppes, embora nossa intenção seja a de apresentar uma alternativa quanto à abordagem semântica. A abordagem que adotamos é, antes, pragmática (cf. Dutra, 2005; 2008, cap. 4). 
Pragmática da investigaÇÃo Gientífica: uma ABordagem nomológiga

Há certa desinformação - mesmo entre os filósofos da ciência - a respeito da tradição behaviorista e suas diversas tendências e variedades teóricas e metodológicas. Há também certa aversão filosófica, digamos, que o próprio termo "behaviorismo" tem despertado depois do advento das recentes teorias cognitivistas. Por tudo isso é conveniente darmos um esclarecimento preliminar sobre o sentido no qual tomamos o termo "behaviorismo" e como entendemos uma abordagem behaviorista.

Assim como Suppes, tomamos o behaviorismo como uma forma de externalismo a respeito das questões relativas à mente, ao comportamento em geral e à ação. Isto é, trata-se de tentar explicar episódios do comportamento humano com base em observações desse próprio comportamento, observações de episódios significativos que, em primeiro lugar, possam conduzir à identificação de padrões de comportamento. Metodologicamente falando, a questão de como pode ser profícua tal abordagem será em parte exemplificada no restante desse artigo.

Não se trata propriamente de polemizar com o cognitivismo atual, nem com o mentalismo tradicional, embora, obviamente, de uma perspectiva behaviorista (isto é, externalista), tal discussão seja uma possibilidade no horizonte. O mais importante, contudo, é mostrar que uma explicação da ação humana com base na observação dela própria pode ser elucidativa e relevante. Ora, uma das questões polêmicas entre as perspectivas internalista (a tradicional e a cognitivista atual) e externalista (as diversas formas de behaviorismo) diz respeito à liberdade, ou seja, se há ou não episódios de ação nos quais os seres humanos exibem liberdade. Via de regra, os behaviorismos são tomados como tentativas de negar a liberdade humana. Mas, ao contrário, desse ponto de vista, trata-se antes de reinterpretar o próprio conceito de liberdade, tentando mais uma vez aquilo que diversas escolas filosóficas procuraram fazer no passado, entre elas o empirismo britânico de autores como Hume, a quem faremos referência adiante.

Em um artigo mais recente, "Rationality, habits and freedom" (2003), Suppes apresentou uma interessante definição de liberdade para padrões de escolha. Ele focalizou principalmente as escolhas individuais por livre associação que interessariam ao mercado e à realização de eleições, por exemplo. Suppes baseia-se na noção de entropia presente na teoria da informação apresentada por Shannon (1948). Segundo essa concepção, a entropia é uma medida da incerteza a respeito dos detalhes de um sistema de símbolos, um tema ao qual voltaremos adiante.

Suppes faz também uma revisão do conceito de liberdade na literatura filosófica, argumentando que a concepção que temos de nós mesmos como seres pensantes e autoconscientes é enganadora na maioria das vezes. Fundamentar o conceito de liberdade nessa pressuposição seria dar margem à psicologia introspectiva que, segundo ele, já se mostrou infrutífera. Os behavioristas não são os únicos na história da psicologia e da filosofia a criticar o método introspeccionista. Freud, por exemplo, mostrou 
que as pessoas quase nunca têm consciência das reais causas de seu comportamento e, logo, obviamente, de suas escolhas. Segundo Suppes (2003, p. 137), temos consciência dos resultados, mas não dos processos, do pensar. Nosso sentimento de liberdade ocorre porque não temos informação sobre o que realmente acontece durante o processo de escolha. Esse sentimento é considerado, por exemplo, também por Skinner, para quem ele é um efeito de determinados comportamentos que envolvem algum tipo de escolha, e não sua causa (cf. Skinner, 1976, p. 11). Ou seja, o sentimento de liberdade tomado em termos introspeccionistas é uma aparência enganadora, e resulta de uma falta de conhecimento sobre os processos que nos conduzem a escolher. ${ }^{2}$

Esta "inconsciência do detalhado processo de pensar," como diz Suppes, a nosso ver, encontra-se também no tipo de racionalidade que estaria presente no comportamento dos cientistas durante sua prática investigativa. Da mesma maneira que ocorre com a dramática escolha de comprar uma casa nova - este é um dos exemplos analisados por Suppes -, uma decisão final no contexto científico se baseia frequentemente em "algo diferente da aplicação de uma computação explícita final, solidamente delimitada ou detalhada" (Suppes, 2003, p. 138). Suppes corrobora a conclusão de vários estudos empíricos e conceituais de acordo com os quais parece nunca ocorrer a produção de uma escolha por meio de um processo de cálculo puramente consciente. Assim, uma teoria da racionalidade fundamentada em qualquer estilo exemplar de deliberação racional, consciente, controlada e completa estaria equivocada sobre o processo de tomada de decisão acerca de problemas práticos ou teóricos (cf. Suppes, 2003, p. 140). Uma alternativa externalista seria então necessária.

Para Suppes, o único mecanismo do pensamento sobre o qual seria possível ter relativa segurança quanto a seu funcionamento é o fluxo de associações livres, caracterizado por certo grau de incerteza inerente aos seus resultados. Embora haja fortes evidências empíricas de que, de fato, a associação seria o mecanismo do pensamento, ${ }^{3}$ mesmo que esse não fosse o caso, a análise do comportamento baseada nas associações tem grande poder de predição - e mesmo de controle - em determinados contextos. É na esfera das associações livres que esperamos encontrar a maleabilidade e a possibilidade de mudanças na estimulação, o que leva à previsão e ao eventual controle dos comportamentos envolvendo a escolha. Essa seria “a convicção fundamental," explica Suppes, "que leva as empresas a competirem por espaço nas prateleiras para anunciar seus produtos" (Suppes, 2003, p. 14,6). O lugar para as livres associações e, consequen-

${ }_{2}$ Cf. Skinner (1990) para uma discussão da noção tradicional e filosófica de liberdade, denunciada pelo behaviorismo radical como um mito, e a reelaboração da noção do ponto de vista behaviorista, em correlação com as noções de controle e contracontrole.

3 Trata-se de resultados obtidos até mesmo por programas cognitivistas de pesquisa (cf. Suppes, 2003). 
Pragmática da inVestigaÇão gientífiga: uma abordagem nomológiga

temente, para a liberdade de escolha dependeria de duas condições: em primeiro lugar, as determinações impostas pelos hábitos devem estar satisfeitas e, segundo, a medida de entropia deve ser, neste caso, diferente de zero.

Assim sendo, o conceito de liberdade que Suppes defende poderia fundamentar uma modalidade de análise do comportamento. Criticando também as abordagens clássicas em economia e na teoria dos jogos, que afirmam que os agentes se comportam de modo a maximizar a utilidade, Suppes enfatiza o papel do hábito na delimitação do repertório de comportamentos. Para ele, nossos hábitos resultam da complexa interação entre nossa herança biológica e o processo de aprendizagem - concepção próxima dos processos de condicionamento (pavloviano e operante) que são descritos por Skinner $(1965 ; 1976)$. Ao mesmo tempo em que faz com que um agente responda mais rapidamente a determinado estímulo, um hábito representa uma restrição ao repertório de comportamento desse agente e, portanto, às escolhas que ele fará. O comportamento que maximizaria a utilidade para um agente pode não estar disponível para ele justamente por causa de um hábito.

Ainda que entendidos como restrições à capacidade de escolha, unicamente os hábitos não seriam capazes de determinar uma escolha. Suppes (2003, p. 14,3) defende que, uma vez saciados os hábitos, outras opções de comportamento ainda restam ao agente. Suppes dá o exemplo do indivíduo que, ao jantar em um restaurante, por hábito, sempre prefere vinho a cerveja. Nesse caso, mesmo que satisfazer o hábito elimine do repertório de possíveis comportamentos a opção de pedir cerveja, se o restaurante tiver uma boa carta de vinhos, o agente ainda poderá escolher, por exemplo, entre beber vinho branco ou tinto. E poderá levar em conta as opções de variedade de uva, safra etc. A entropia, desse modo, será diferente de zero, deixando espaço para associações livres. Por isso, a definição filosófica clássica de liberdade como ausência de restrições não seria adequada. A nosso ver, a análise de Suppes sugere que o próprio conceito de liberdade teria de ser compreendido contextualmente. Isto é, os diversos contextos de ação é que determinam a possibilidade de escolha e, logo, de (alguma) liberdade. O exemplo acima ilustra isso. O contexto impõe restrições e, ao fazê-lo, abre possibilidades de ação e escolha.

Uma concepção tradicional de liberdade como ausência de restrições, concepção à qual Suppes se refere, é encontrada, por exemplo, em Hume. Ao tratar da liberdade relativa às ações voluntárias, Hume afirma que não há matéria para disputas, pois não entra em questão o fato reconhecido e evidente de que as ações tenham conexões com motivos, inclinações e circunstâncias, e que o grau de uniformidade é tal que as ações possam ser inferidas destas condições. Desse modo, Hume aceitaria o pressuposto fundamental da maioria das abordagens behavioristas de que o comportamento humano é determinado por condições (em linguagem contemporânea) genéticas e 
ambientais. A concepção de liberdade humiana, contudo, diz respeito a "um poder de agir ou de não agir, segundo as determinações da vontade” (Hume, 1996, p. 73). Hume explica essa definição dizendo que a liberdade é a condição daquele que não se encontra preso e encarcerado. Segundo ele, a característica definidora de liberdade seria a ausência de restrição física.

Suppes reconhece que há elementos importantes nessa concepção. Por outro lado, ele argumenta que a incerteza é uma característica essencial da liberdade. Ele propõe então que a entropia seja utilizada como medida natural da liberdade de escolha individual, bem como da liberdade de mercados e eleições, ou seja, como medida da incerteza inerente a uma escolha individual, aos resultados de uma eleição e às transações comerciais. Contudo, isso não muda o fato de que, mesmo na ausência de restrições físicas patentes, as escolhas continuem dependendo da história a longo prazo e dos eventos imediatos anteriores à escolha. Nesse mesmo sentido, Skinner (1976, p. 59-60, 125 e 216-20) afirma que, além da restrição física ou sua ameaça, os esquemas de reforço presentes no condicionamento operante são os principais responsáveis pela determinação de nossas escolhas. Mas eles não interferem no sentimento de liberdade experimentado pelas pessoas. E por isso deixam de ser discutidos pela literatura sobre a liberdade. ${ }^{4}$

O objetivo de Suppes é fornecer uma medida para avaliar o padrão usual das escolhas que fazemos. Ele recorre ao conceito de hábito para caracterizar a noção de racionalidade. Os hábitos constituiriam as restrições (restraints) - no sentido matemático padrão de restrição (constraints) - envolvidas em todas as escolhas que as pessoas fazem e que, em geral, não são acompanhadas de atenção consciente (cf. Suppes, 2003, p. 143). Os hábitos apresentam restrições que são ordinariamente satisfeitas, porém, sem determinar a escolha.

Os hábitos têm algumas propriedades. A primeira delas é, segundo Suppes, que são físicos e estão presentes inclusive na matéria não animada. A segunda propriedade é que os hábitos funcionam melhor quanto mais repetidos forem. Essas duas propriedades podem ser observadas, por exemplo, em uma trilha que fica mais aberta à medida que mais pessoas passam por ela. A terceira propriedade dos hábitos é que eles fazem diminuir a atenção consciente do sujeito quando de sua realização. É nesse sentido que Suppes afirma que "somente os ineptos são cônscios de suas escolhas finais," coadunando-se com a velha noção do senso comum de que "se anda melhor quando não se pensa nas próprias pernas" (Suppes, 2003, p. 145).

4 Cf. também Skinner (1990 [1971]) para uma discussão mais abrangente dessa problemática. 
Pragmática da inVestigaÇão gientífiga: uma abordagem nomológiga

Depois da estipulação de um hábito e da constatação de que a entropia não é zero, abre-se espaço para um conjunto de escolhas - a associação livre. Suppes diz a este respeito: "sempre que o nível de caracterização de um hábito tem entropia diferente de zero, o conjunto remanescente e não trivial de escolha deixa espaço para associações" (Suppes, 2003, p. 146). A associação de ideias tem sua discussão filosófica clássica também em autores como Hume (1996, p. 19). Segundo ele, há três princípios de associação de ideias, a saber, semelhança, contiguidade e causa e efeito. Suppes referese à expressão 'livre associação' como uma concepção hierarquizada de como é possível fazer escolhas racionais. O ponto central para Suppes é a necessidade da compreensão e do reconhecimento do papel do hábito e da associação livre ou, ainda mais, "daquilo que não chega à consciência, mas que é expresso por meio das ações em nossas reais escolhas" (Suppes, 2003, p. 151). O conhecimento desse processo pode auxiliar a eliminar as descrições de escolhas como instintivas ou escolhas nas quais o agente não é capaz de explicar os motivos que o levaram a tal comportamento.

Entendida nesses termos, a publicação de um artigo científico pode ser tomada como um evento de escolha por associação, na medida em que o cientista, pelo menos no contexto da ciência normal (no sentido kuhniano do termo; cf. Kuhn, 1996, cap. 3), tem a sua disposição um número limitado de tipos de artigos que pode publicar. Este será um tema que desenvolveremos no restante deste trabalho. Contudo, antes, é necessário também fazermos um comentário preliminar sobre a forma como encaramos os contextos de investigação científica, contextos nos quais se dão as escolhas e decisões dos cientistas sobre a publicação de artigos, seu conteúdo e seus propósitos. Esta é uma parte importante da própria atividade científica, uma vez que, por vezes, a pesquisa pode prosseguir a partir de sua comunicação a outros pesquisadores, da colaboração entre eles e contando com desdobramentos que os próprios autores de uma teoria científica não perceberam como possíveis, mas que outros podem perceber.

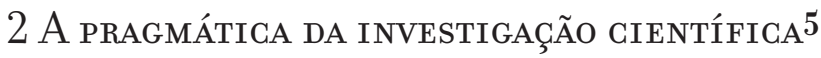

A concepção de modelo científico que pressupomos aqui é alternativa aos autores que defendem a abordagem semântica, como Bas van Fraassen (1980) que, em parte, se inspira nos trabalhos do próprio Suppes. Van Fraassen diz que uma teoria científica deve ser entendida como uma coleção de modelos semânticos, isto é, o tipo de estrutu-

5 Alguns dos temas principais desenvolvidos aqui são retomados de Dutra (2006), "Comportamento intencional e contextos sociais: uma abordagem nomológica." Trata-se daqueles aspectos que permitem sua aplicação ao caso dos padrões de comportamento investigativo nas ciências. 
ra que permite interpretar uma linguagem de primeira ordem. Entretanto, o sentido em que, ordinariamente, os cientistas utilizam o termo 'modelo' sugere uma noção mais ampla. Do ponto de vista da pragmática da investigação (cf. Dutra, 2008, cap. 4; cf. ainda Dutra, 2005), os modelos seriam, antes, estruturas abstratas diferentes dos modelos semânticos. Tais estruturas são descritas em leis (ou enunciados nomológicos), que relatam o comportamento de determinado sistema.

Por exemplo, na física clássica, o modelo do plano inclinado é uma estrutura deste tipo, isto é, um sistema físico possível segundo a teoria e cujo comportamento pode ser descrito pelas leis implicadas pela teoria (a mecânica newtoniana, exatamente). Além disso, do ponto de vista pragmático, os modelos seriam projetos de experimentos, antecipações deles e, como diz Nancy Cartwright (2003), projetos de máquinas nomológicas. Deste modo, a noção de modelo que estamos pressupondo é esta, ou seja, que os modelos científicos são estruturas abstratas admitidas como possíveis por determinada teoria científica, de tal forma que certas leis descrevem o comportamento do sistema correspondente ao modelo.

A noção de pragmática da investigação científica aqui discutida adota uma perspectiva ao mesmo tempo intencionalista e nomológica, e é baseada em parte na teoria que Howard Rachlin apresenta em Behavior and mind (1994), que é por ele mesmo denominada behaviorismo teleológico. A teoria de Rachlin procura explicar, predizer e controlar o comportamento manifesto, inclusive os padrões mais complexos, o que inclui então os padrões de comportamento investigativo, como aqueles que encontramos na atividade científica.

Rachlin se opõe à psicologia cognitiva que, segundo ele, procura descobrir e estudar os mecanismos internos responsáveis pelo comportamento. ${ }^{\mathbf{6}} \mathrm{O}$ behaviorismo teleológico, por sua vez, é baseado em uma concepção aristotélica da causação, segundo a qual as causas finais são tão importantes quanto as causas eficientes nas explicações científicas. A diferença entre a psicologia cognitiva e o behaviorismo teleológico, diz Rachlin, é, portanto, a mesma que há entre a busca de causas eficientes e a busca de causas finais do comportamento.

A psicologia cognitiva, enquanto uma ciência das causas eficientes, procura apontar os mecanismos internos que seriam responsáveis pela maneira como um sujeito se comporta, sente e pensa da forma como o faz. Uma explicação do comportamento em termos de causas finais, por outro lado, como aquela dada pelo behaviorista teleológico, "toma a forma de um objetivo ou propósito - o lugar desse processo particular em um

6 Em uma obra anterior, contudo, Judgment, decision, and choice: a cognitive/behavioral synthesis (1989), Rachlin busca uma conciliação entre as perspectivas behaviorista e cognitivista. Mas seu behaviorismo teleológico, defendido em Behavior and mind: the roots of modern psychology (1994), não contempla a perspectiva cognitivista. 
Pragmática da inVestigaÇão gientífiga: uma abordagem nomológiga

contexto molar, ou mais amplo, mais geral," diz Rachlin (1994, p. 7, nota). Assim, sua teoria é também, como ele mesmo enfatiza, claramente intencional (cf. Rachlin, 1994, p. 15-6). O comportamento é intencional se tem lugar em um contexto no qual uma causa final é identificada como o fator mais saliente.

Rachlin compreende um processo mental específico em função de seu lugar em um contexto mais amplo, portanto, aquilo que permite resolver o problema de que as ações específicas de um indivíduo são observáveis, enquanto que o contexto mais amplo no qual se dá tal ação é frequentemente inobservável. O comportamento molar, diz Rachlin, é o comportamento estendido no tempo, e uma ação e seu contexto são acontecimentos externos.

A análise molar de Rachlin diz respeito a padrões de comportamento complexos e de longo prazo, aos quais se referem termos como "amor" e "crença", por exemplo. Ora, como o próprio Rachlin reconhece, tais padrões de comportamento requerem alguma organização social. O amor, por exemplo, diz ele, é um padrão dos mais complexos, pois envolve não apenas uma pessoa e um sistema social, mas duas pessoas e um sistema social. De acordo com Rachlin, a ideia de que o amor - assim como toda vida mental ou qualquer padrão de comportamento - é realização (performance) é a essência do behaviorismo teleológico (Rachlin, 1994, p. 17-18).

Rachlin explica em que sentido aceitável podemos conceber as causas finais do comportamento e dar para ele explicações teleológicas e intencionais. Para a ciência moderna, as causas finais deveriam ser eliminadas, por parecerem estar ligadas a concepções animistas e antropomórficas dos fenômenos naturais. Além disso, a causa final parece ser uma causa eficiente revertida, isto é, uma causa que estaria temporalmente colocada depois de seu efeito. Para Rachlin, não se trata disso. Uma causa final do comportamento é apenas o contexto mais amplo no qual determinado comportamento se encaixa (Rachlin, 1994, p. 22).

Entretanto, seguindo a estratégia de análise de Rachlin, explicar um comportamento requer muitas vezes um prazo que pode ser longo demais. Muitos dos comportamentos que queremos explicar - e talvez, realmente, a maioria deles - são realizações de fato ainda não terminadas, ou seja, realizações que parecem requerer uma análise molar de prazo mais curto, sob pena de termos apenas uma psicologia post mortem, como no caso de podermos dizer que duas pessoas se amam se, a muito longo prazo, se comportam de determinadas formas socialmente associadas ao comportamento amoroso.

Esta é uma limitação importante da abordagem de Rachlin, limitação que torna o behaviorismo teleológico, tal como apresentado por ele, uma estratégia investigativa pouco útil em uma ciência empírica do comportamento. Uma concepção molar do comportamento pode ser vantajosa se associarmos um padrão menor de comportamento com um padrão maior. Mas uma interpretação molar do comportamento não precisa- 
ria se restringir ao tempo. Outros aspectos relativos à realização também poderiam ser levados em conta.

A concepção alternativa que apresentamos consiste em tomar um episódio de comportamento em sua relação com dado contexto social. Nesse contexto, outros padrões de comportamento intencional também ocorrem, estando o padrão que desejamos investigar ligado àqueles na medida em que todos estão incluídos em uma organização social específica - o que é uma ideia do próprio Rachlin, mas da qual ele não tira as consequências todas que, a nosso ver, poderia tirar. Essa é então a alternativa que procuramos desenvolver em suas linhas gerais. Além de representar também a possibilidade de explicações intencionais do comportamento, essa alternativa representaria ainda a possibilidade de oferecer explicações nomológicas para o comportamento intencional. Além de uma explicação intencional ser, desse ponto de vista, uma explicação teleológica, explicamos um episódio de comportamento ao remetê-lo a um contexto no qual ele se ajusta, contexto este que, por sua vez, se encaixa em determinado sistema social.

A ideia é a de que devemos procurar mostrar que um fator saliente de determinado contexto é a causa final de um evento que, em primeiro lugar, foi explicado teleologicamente. Por sua vez, tal finalidade pode também estar relacionada com outra causa final, mais inclusiva, no sentido de Rachlin, isto é, com um fator saliente de um contexto maior a ser considerado. Assim, para os padrões de comportamento, na medida em que consideramos contextos sociais mais abrangentes, há causas finais mais remotas que permitem explicar tais padrões. É necessário apenas, contudo, que os padrões de comportamento e os contextos sociais considerados sejam reprodutíveis em determinado sistema ou organização social.

Metodologicamente falando, é preciso que os eventos relacionados como causa final e efeito sejam dados em conjunção constante ou, em termos mais exatos, que a relação entre eles possa ser relatada em termos funcionais. A expressão 'causa final', nesse caso, se refere à variável independente de uma relação funcional que diz respeito à ligação de dado padrão de comportamento com um contexto social. Quando narramos desse modo a relação entre padrões de comportamento e contextos sociais - isto é, em termos teleológicos -, o comportamento é ipso facto interpretado de forma intencional, no sentido externalizado que defendemos.

Essa abordagem também se coaduna com aquela defendida por Suppes, que comentamos na seção precedente. Pois os fenômenos comportamentais aos quais Suppes se refere, como decisões de mercado (a compra de um produto ou a escolha de consumo repetido de um tipo de produto) e eleições, são acontecimentos sociais que se ajustam em determinado sistema (a sociedade moderna, democrática e de consumo). Trata-se de fenômenos sociais e comportamentais reprodutíveis nesse sistema social. 
Pragmática da inVestigaÇão gientífiga: uma abordagem nomológiga

Como veremos adiante, o mesmo vale para a investigação científica em geral (cf. Dutra, 2008, cap. 8) e, em particular, para aquela atividade dentro dela que tomamos em consideração, a saber, a publicação de artigos científicos.

Duas questões fundamentais precisam, contudo, ser respondidas se essa abordagem nomológica ao comportamento intencional for aceitável. Em primeiro lugar, devemos estabelecer do modo mais claro possível que tipo de relação teleológica pode haver entre determinados padrões de comportamento e certos contextos sociais, em dado sistema ou organização social. Em segundo lugar, é preciso mostrar que tais relações entre certos padrões de comportamento e certos contextos sociais são não apenas teleológicas, mas também nomológicas. Isto é, a ocorrência de tais padrões de comportamento deve ser um fenômeno reprodutível e reincidente nos contextos sociais considerados, dado um sistema social, segundo certas relações funcionais claramente enunciadas. Em suma, é preciso mostrar que são possíveis enunciados nomológicos que descrevem a ocorrência de certos padrões de comportamento em determinados contextos sociais, dado um sistema social.

É relativamente fácil ver como isso vale para aqueles fenômenos sociais da escolha relacionada com o consumo e o voto, dos quais fala Suppes. Mas é menos óbvia a validade e a propriedade dessa abordagem para o caso da investigação científica. Nesse caso, certos pressupostos intelectualistas tradicionais e cognitivistas de hoje (como de que as decisões sobre o conteúdo de um artigo científico não dependem de variáveis ambientais, mas apenas do entendimento do autor sobre o tema) nos levariam a pensar que a atividade científica naquilo que ela possui de mais fundamental se furtaria a tais contingências ambientais e sociais.

A primeira das questões acima apontadas se refere ao fenômeno social e comportamental que denominamos encaixamento. Há um padrão de comportamento (a ser explicado) que se encaixa necessariamente em um contexto social que contém outros padrões de comportamento, um dos quais, por sua vez, deve ser identificado como a causa final daquele padrão de comportamento a ser explicado. Ao dizer que um padrão se encaixa necessariamente em um contexto, queremos dizer que tal padrão só é compreensível em relação a tal contexto (ou, eventualmente, a algum outro), mas não isoladamente, nem em relação a qualquer contexto dado. Em termos mais exatos, um padrão de comportamento pode ser definido pela classe dos contextos sociais nos quais ele se encaixa. Por se encaixar em um contexto social tal como acima definido, um padrão de comportamento está necessariamente ligado a outros.

Aqui, retomarmos os casos discutidos por Suppes ajudaria mais uma vez. Pois apenas na sociedade de consumo na qual está vigente um sistema democrático é que os comportamentos aos quais ele se refere (como decisões de compra e voto) podem se encaixar. É necessariamente em relação a tal contexto social mais amplo que os com- 
portamentos em questão podem ser compreendidos. Embora tais comportamentos possam ser possíveis também em outras formas de organização social, nelas eles apenas se ajustariam precariamente, mas não se encaixariam necessariamente da forma como acima explicamos esse fenômeno.

Essa abordagem, assim como aquela de Rachlin, é molar, mas não no sentido temporal estrito proposto por aquele autor. A nosso ver, comportamentos molares podem ser tomados em consideração em um sentido puramente matemático, como é o caso, por exemplo, da lei de igualação (matching law; cf. Herrnstein, 1997, p. 22, 68). De acordo com essa teoria, um comportamento (ou resposta) é proporcional à frequência relativa do reforço que ele oferece. Deste ponto de vista, a escolha, por exemplo, é medida como uma razão de comportamento. Ela é compreendida como um comportamento no contexto de outro comportamento (Herrnstein, 1997, p. 22), que é uma ideia fundamental também da alternativa que estamos tentando desenvolver e apresentar, como vimos acima.

Por exemplo, tomemos duas respostas alternativas, $A$ e $B$, e o reforço associado a cada uma delas, em certo contexto de ação, observado durante certo período de tempo. Ora, segundo a abordagem da lei de igualação, um indivíduo vai empregar seu tempo fazendo $A$ ou $B$ de forma proporcional aos diferentes reforços oferecidos, respectivamente, por $A$ e $B$. Supondo que o comportamento total desse contexto permaneça invariante, então, segundo a lei de igualação, vale a seguinte relação funcional, na qual $T$ se refere ao tempo gasto com cada comportamento e $R$ se refere ao reforço oferecido por cada comportamento: ${ }^{\mathrm{TA}} \mathrm{D}_{\mathrm{TB}}={ }^{\mathrm{RA}} \mathrm{D}_{\mathrm{RB}}$.

Generalizando esse modo de compreender os padrões de comportamento, e considerando-os uns em relação aos outros, temos que, em um contexto social, os diferentes padrões que o compõem estarão ali reunidos segundo certas relações funcionais semelhantes à lei de igualação. A realização total desse contexto de ação será o somatório das realizações parciais de cada padrão de comportamento, de tal sorte que a realização parcial de cada padrão também tenha como finalidade compor a totalidade da realização desse contexto.

Quanto à questão da reprodutibilidade dos contextos sociais de ação em certos sistemas sociais, devemos dizer que o caráter nomológico da explicação teleológica dada ao comportamento depende não somente da interpretação molar dos padrões de comportamento em relação a um contexto social, mas da possibilidade de reproduzir tais contextos em certa organização social. A existência de certas instituições em certas organizações sociais é aquilo que garante a reprodutibilidade de padrões de comportamento e o caráter nomológico de uma explicação para eles. As observações de tal sistema social levam a generalizações empíricas. Por outro lado, é apenas em virtude de tais explicações possuírem caráter nomológico que elas são realmente teleológicas - e, logo, 
Pragmática da inVestigaÇão gientífiga: uma abordagem nomológiga

intencionais. Se certa prática não for reprodutível - e, portanto, predizível - em certa organização social, então ela não será relevante para explicarmos outros eventos.

Uma aplicação dessa perspectiva à análise da pragmática da investigação resulta, entre outras coisas, no seguinte: determinado comportamento investigativo (dos cientistas de certa especialidade) poderá ser compreendido na medida em que se encaixar em um contexto mais amplo, que é aquele do programa de pesquisa ao qual tais cientistas aderiram. Tal programa de pesquisa, por sua vez, se encaixa em uma tradição científica, identificada como a especialidade em questão em uma perspectiva histórica, isto é, como determinada ciência que se supõe continuar através do trabalho de gerações e gerações que se sucedem em tal tradição. Por sua vez, tais disciplinas ou tradições de investigação profissionalizada podem ser compreendidas no contexto mais amplo da cultura ocidental e nas práticas científicas que ela consolidou.

Além desse aspecto mais geral do entendimento da atividade científica, a análise da pragmática da investigação pode identificar padrões mais específicos de investigação, e remetê-los aos contextos científicos adequados, de acordo com os quais tais comportamentos investigativos podem ser compreendidos de forma teleológica e intencional, tal como descrevemos acima para os padrões de comportamento em geral. $\mathrm{Na}$ medida em que pudermos então estabelecer correlações entre determinados padrões do comportamento investigativo, poderemos então identificar regularidades do comportamento científico, que são o tema que nos interessa e, entre tais regularidades, aquela relativa à publicação de artigos científicos.

\section{As trajetórias de investigação e as Gadeias de Markov}

Além dos contextos sociais mais amplos nos quais a prática científica se insere, podemos identificar outra unidade molar de comportamento que se presta à análise: a trajetória de investigação. Se, como dissemos anteriormente, a atividade científica pode ser entendida por meio de sua relação com os modelos, podemos definir a trajetória de investigação de determinado modelo como a totalidade do comportamento científico realizado sobre esse modelo. Entretanto, para termos uma abordagem quantitativa semelhante àquela apresentada por Suppes (2003, p. 161-2), devemos restringir essa definição ao comportamento verbal do cientista. Consideremos, assim, a trajetória de investigação de determinado modelo como o conjunto de artigos científicos escritos com o objetivo de definir, reelaborar, ampliar, ou refutar esse modelo.

Dessa forma, o segmento de comportamento científico verbal (cf. Skinner, 1992) adequado para uma análise desse tipo é o artigo científico. Assim como no caso da abordagem de Suppes e dos resultados que ele veiculou, tirando deles consequências de 
caráter mais geral tanto do ponto de vista psicológico, quanto do ponto de vista filosófico, nossa abordagem requer também um estudo empírico. Isto é, trata-se de fazer uma pesquisa empírica, analisando o comportamento verbal dos cientistas, através do exame de trajetórias de publicações. Essa pesquisa foi realizada e seus resultados estão veiculados em outro trabalho (cf. Dutra et al., no prelo). No restante dessa seção, discutimos os pressupostos metodológicos que permitiram aplicar a este caso a abordagem a que antes nos referimos.

Tomando como foco da publicação de artigos científicos o desenvolvimento e a aplicação de modelos, em primeiro lugar, definimos certas categorias com as quais podemos classificar os diversos artigos publicados por um cientista e, assim, termos uma forma de descrever sua trajetória de publicações como uma instância de sua trajetória de investigação. Os tipos de artigos são os seguintes:

(Tipo A) Artigo que propõe um novo modelo para lidar com um fenômeno ou conjunto de fenômenos.

(Tipo B) Artigo no qual generalizações e/ou pequenas correções no modelo ou em uma aplicação do modelo são apresentadas. Essas generalizações e correções podem se referir diretamente ao modelo, tal como proposto em um artigo do tipo A, ou a uma aplicação dele, proposta em um artigo dos tipos C ou E.

(Tipo C) Artigo que propõe uma aplicação empírica do modelo. Esse tipo de artigo mostra que o modelo apresentado em um artigo do tipo A pode ser útil para explicar algum outro grupo de fenômenos dentro do mesmo domínio de conhecimento em que o modelo foi originalmente proposto.

(Tipo D) Artigo que apresenta explicações sobre a aplicação do modelo. Estas explicações podem se referir a uma aplicação do modelo apresentada em um artigo do tipo C ou do tipo E.

(Tipo E) Artigo que propõe uma aplicação empírica do modelo em uma área do conhecimento diferente daquela em que o modelo foi originalmente proposto. Este tipo de artigo é semelhante a um do tipo $\mathrm{C}$, mas trata de um grupo diferente de fenômenos.

(Tipo F) Artigo que apresenta resultados experimentais da aplicação do modelo; pode se referir a um artigo do tipo C ou do tipo E.

(Tipo G) Artigo que divulga ou revisa o modelo e/ou suas aplicações. Seu propósito é tornar pública a pesquisa em desenvolvimento.

(Tipo H) Artigo em que uma falha em um modelo é detectada e corrigida. Esta correção pode ser por meio de uma nova aplicação do modelo (em caso de falha em um modelo concorrente) ou por meio de uma correção no modelo ou nova explicação do fenômeno. 
Pragmática da inVestigaÇão gientífiga: uma abordagem nomológiga

Uma trajetória de investigação passa a ser então a sequência temporal dos artigos-tipo aos quais seus artigos-ocorrência pertencem. Os artigos-tipo são tomados, por exemplo, em analogia com as classes de palavras de uma língua natural (adjetivos, substantivos, verbos etc.) e as trajetórias de investigação seriam análogas às estruturas de frases construídas a partir dessas classes. Um exemplo de trajetória de investigação, com dez artigos, poderia então ser o seguinte:

$$
T I=(\mathrm{A}, \mathrm{C}, \mathrm{C}, \mathrm{B}, \mathrm{E}, \mathrm{C}, \mathrm{H}, \mathrm{G}, \mathrm{F}, \mathrm{F}, \mathrm{F}) .
$$

Nessa sequência, cada letra corresponde ao tipo do artigo naquela posição. A trajetória de investigação desse exemplo começa com um artigo A e se desenvolve até terminar em um artigo $\mathrm{F}$.

Através da pesquisa realizada, pudemos determinar qual seria, digamos, a gramática, ou talvez, melhor dizendo, a pragmática, das trajetórias de investigação. As definições que acabamos de dar se fundamentam em algumas outras hipóteses preliminares que também precisam ser comentadas.

Por exemplo, tomemos a hipótese de que uma trajetória de investigação se inicie com um artigo do tipo A e termine com um artigo do tipo F. Claramente, essa hipótese poderia ser refutada no curso da pesquisa, uma vez que, assim como na maioria dos casos, há grande distância entre a gramática e a pragmática de uma língua natural, é plausível que a pragmática das trajetórias de investigação seja irregular. Esse é um problema metodológico comum nas ciências e, de fato, como sabemos, requer aproximações que são possíveis com base na teoria empregada e que dirige a pesquisa.

Apesar de tais dificuldades metodológicas, é importante ressaltar que nossa abordagem não deixa de ser nomológica. Isto é, como ficará claro na sequência, nossa estratégia consistiu em determinar a probabilidade com que determinado artigo-tipo seja seguido de outro. Para tanto, foi necessário compreender as trajetórias de investigação como processos estocásticos denominados cadeias de Markov. 7

Seja $l$ uma variável numérica que assuma valores inteiros. Se cada valor de $l$ estiver associado a um número real $p_{l}$ não-negativo, tal que $\sum_{l} p_{l}=1, l$ será uma variável aleatória discreta, tendo $p_{l}$ como sua distribuição de probabilidade.

Uma variável aleatória que dependa de um parâmetro $t$ (sendo $t$ o tempo) é chamada de variável estocástica. Por exemplo, a variável estocástica xt pode assumir valores inteiros, e $t$ os valores $0,1,2,3, \ldots$ Assim, podemos definir um processo estocástico pela distribuição de probabilidade conjunta

7 Para uma apresentação a respeito de como são realizados os cálculos de entropia e de obtenção de uma matriz de transição, cf. Tomé e Oliveira, 2001. 


$$
P_{l}\left(n_{0}, n_{1}, n_{2}, \ldots, n_{l}\right)
$$

de que $x$ t tome o valor no no instante $t=0$, o valor $n 1$ no instante $t=1$, e assim por diante.

Se a probabilidade condicional

$$
P_{l}{ }_{1}\left(n_{l+1} \mid n_{0}, n_{1}, n_{2}, \ldots, n_{l}\right)
$$

for igual à probabilidade condicional

$$
P_{l}+_{1}\left(n_{l+1} \mid n_{l}\right)
$$

de que a variável estocástica $x_{t}$ tome o valor $n_{l+1}$ no instante $t=l+1$, dado que ela tenha tomado o valor $n l$ no instante $t=l$, então esse processo estocástico é uma cadeia de Markov de primeira ordem (cf. Tomé e Oliveira, 2001). Em outras palavras, uma cadeia de Markov de ordem $k$ é um processo estocástico no qual a probabilidade condicional de $x t$ tomar determinado valor em certo instante depende unicamente do valor que ela tenha tomado nos $k$ instantes anteriores.

Em uma trajetória de investigação tal como a interpretamos acima, o valor $n l$ da variável estocástica $x_{t}$ corresponde ao artigo-tipo do artigo-ocorrência na posição $t=1$ da trajetória. Chamemos de espaço de estados $(S)$ o conjunto de valores que $x_{t}$ pode assumir. Em uma abordagem pragmática da investigação científica, $S$ corresponde ao conjunto de artigos-tipo. O espaço de estados que estamos considerando em nossa abordagem é $S=\{\mathrm{A}, \mathrm{B}, \mathrm{C}, \mathrm{D}, \mathrm{E}, \mathrm{F}, \mathrm{G}, \mathrm{H}\}$.

A probabilidade condicional $P_{l^{+}}\left(n_{l+1} \mid n_{l}\right)$ é chamada de probabilidade de transição do estado $n_{l}$ para o estado $n_{l+1}$. Em processos markovianos cujas probabilidades de transição não variam com o tempo, podemos nos referir a elas, abreviadamente, utilizando a seguinte forma: $T\left(n_{l+1}, n_{l}\right)$. Além disso, considerando o espaço de estados de uma cadeia de Markov, as probabilidades de transição podem ser expressas na forma de uma matriz de transição $(T)$, com as seguintes propriedades:

$$
T_{i j} \geq 0 \quad \text { e } \quad \sum_{j} T_{i j}=1 .
$$

Dessa maneira, dada a matriz de transição para determinado processo markoviano, é possível calcular o estado estacionário do processo, isto é, um vetor representando as probabilidades de transição quando o processo é repetido por um número de vezes que tende ao infinito. Esse vetor é calculado por meio do método algébrico (cf. Tomé \& Oliveira, 2001), que envolve a determinação dos autovalores e autovetores de T. Em uma trajetória de investigação, o estado estacionário representa, mutatis mu- 
Pragmática da inVestigaÇão gientífiga: uma abordagem nomológiga

tandis, as probabilidades de os investigadores escolherem publicar artigos-ocorrência de determinados artigos-tipo se a investigação continuar indefinidamente.

Outra medida importante no estudo de uma cadeia de Markov é o cálculo da entropia. Dada uma matriz de transição, a entropia é definida por:

$$
H=-\sum_{i} p_{i} \log p_{i}
$$

A equivalência entre as possibilidades de desenvolvimento de um sistema constitui uma situação de entropia máxima. A quantidade de informação veiculada por uma mensagem, de acordo com Shannon (1948), é igual à quantidade de incerteza (entropia) contida em seus símbolos componentes. Por isso, quanto mais incerto é o desenvolvimento de um sistema simbólico, maior a quantidade de informação veiculada por mensagens construídas a partir dele.

Uma vez estabelecido o aparato matemático, como acabamos de ver, para analisarmos as trajetórias de publicação de artigos, a pesquisa empírica foi projetada em duas etapas. A primeira etapa se subdividiu em duas linhas de trabalho, sendo a primeira delas a coleta de dados a partir do exame das publicações de um autor com grande número de artigos publicados ao longo de quase duas décadas (mais de cem artigos) e a segunda, o desenvolvimento do software para o cálculo da matriz de transição. ${ }^{8}$ A segunda etapa foi o processamento e interpretação dos dados utilizando o software desenvolvido na primeira etapa.

A trajetória identificada e escolhida foi analisada manualmente, sendo que cada artigo foi classificado de acordo com um artigo-tipo (cf. lista acima apresentada). A trajetória foi dividida em duas séries menores de artigos, sendo que cada uma delas corresponde a uma variação sobre um modelo inicial comum às duas séries. Os dados assim gerados foram usados para alimentar o software para o cálculo da matriz de transição. 9

Paralelamente à identificação e processamento da trajetória de investigação, foi desenvolvido o ReMarkov, o software que permitiu realizar diversas análises relacionadas a processos markovianos. O ReMarkov está escrito em Ruby, ${ }^{10}$ uma linguagem de programação open source, gratuita, interpretada, orientada para objetos e de tipagem dinâmica. O ReMarkov fornece como output a matriz de transição, os valores de entropia, e o estado estacionário para uma trajetória de investigação. ${ }^{\mathbf{1 1}}$

8 De agora em diante, referir-nos-emos a esse software por seu nome provisório, ReMarkov.

9 Para detalhes sobre os resultados, cf. Dutra et al., no prelo.

10 http://www.ruby-lang.org/.

11 Tanto o código-fonte quanto o executável e a interface on-line do ReMarkov estão hospedados na página do Grupo de Estudos sobre Conhecimento e Linguagem (UFSC/CNPq): http://www.cfh.ufsc.br/ necl. 
O processamento da trajetória de investigação pelo ReMarkov gerou uma matriz não ergódica (cf. Suppes, 2003), o que significa que o estado estacionário do processo não pôde ser calculado. Entretanto, nas duas séries analisadas, foi encontrada uma alta frequência de artigos do tipo $\mathrm{F}$ (que comunicam resultados experimentais) no fim da trajetória. Esse resultado sugere que, nas disciplinas em que, de fato, há a separação entre a proposta de um modelo (tipo A) e sua aplicação empírica (tipo F), um aumento na publicação de resultados empíricos pode sinalizar o fim da pesquisa sobre o modelo em questão.

Esses procedimentos metodológicos permitiram obter, em primeiro lugar, um procedimento (ou protocolo) experimental para o estudo empírico da pragmática da investigação científica. Além disso, permitiram desenvolver uma ferramenta flexível para a análise de processos Markov - o ReMarkov. Ao disponibilizarmos gratuitamente esse software e seu código-fonte, estamos motivando outros estudos não somente na área da pragmática da investigação científica, mas também em todas as áreas que envolvam cadeias de Markov.

Essa estratégia metodológica viabiliza uma abordagem nomológica da investigação científica. O cálculo do estado estacionário das trajetórias de investigação nos dá as leis, digamos, da pragmática da investigação científica, isto é, as distribuições de frequências para os artigos-tipo que refletem o que aconteceria caso a investigação continuasse indefinidamente, ou seja, tendesse ao infinito. De posse dessas leis ou, melhor dizendo, enunciados nomológicos probabilísticos, podem-se projetar experimentos futuros, entre eles tomar uma trajetória em andamento e fazer uma predição sobre qual será o próximo artigo-tipo daquela trajetória.

Por fim, vale notar que, procedendo deste modo, podemos comparar a abordagem por meio de cadeias de Markov com a lei de igualação, a que nos referimos antes neste artigo. De fato, estamos lidando com mecanismos de reforço do tipo descrito por Herrnstein (1997), mecanismos que operam em situações de escolha determinada por associações livres. Afinal, um cálculo semelhante ao da lei de igualação é realizado no momento em que se calcula a frequência relativa de cada transição de um processo markoviano.

Em conjunto, os resultados empiricamente obtidos são uma amostra das possibilidades apresentadas pela abordagem nomológica à pragmática da investigação científica. Embora diversos campos de conhecimento voltados para o estudo da própria ciência tenham, a partir de diferentes pontos de vista, reconhecido certa ordem nos procedimentos investigativos, poucas foram as tentativas em descrevê-la nomologicamente. A pesquisa a que nos referimos aqui deu um primeiro passo nessa direção. 
Pragmática da inVestigaÇão Gientífiga: uma abordagem nomológiga

\section{ConsideraÇões finais: o VALOR dos mÉtodos matemáticos}

Uma das dificuldades relativas a um estudo empírico da ciência, assim como, em geral, da ação humana - ao contrário do estudo dos fenômenos naturais praticado pela física e outras ciências matematizadas - está na identificação do fenômeno propriamente ao qual um procedimento matemático pode ser aplicado. Trata-se de uma dificuldade metodológica geral da psicologia e das ciências humanas.

Naquelas ciências humanas nas quais a aplicação de métodos matemáticos tem sido considerada relativamente bem sucedida - em especial, a economia e a psicologia experimental de orientação skinneriana - decisões metodológicas tiveram de ser tomadas, envolvendo a própria concepção do fenômeno a ser estudado.

O temor sempre presente nas ciências humanas é que tais decisões metodológicas desfigurem de tal modo o próprio objeto de estudo que, no final, não estejamos mais tratando daquilo que importava tratar. Uma longa tradição na filosofia da ciência - reforçada hoje por eminentes filósofos da mente que defendem o caráter não nomológico da intencionalidade, entre eles, por exemplo, Donald Davidson - tende a argumentar que os próprios objetos de estudo das ciências humanas são refratários a qualquer tentativa de tratamento matemático. E por isso, nesse contexto de discussões epistemológicas, programas de pesquisa como o de Skinner são considerados meras tentativas de reduzir de forma mutiladora as ciências humanas ao modelo das ciências naturais mais bem sucedidas, como a física.

O presente artigo e a pesquisa a ele ligada não desconsideraram esses aspectos, mas procuraram encontrar uma forma de identificar um objeto de estudo empírico da prática científica que se prestasse a um tratamento matemático de forma a ainda contribuir para compreender a própria prática científica e a produção de conhecimento como uma das formas da ação humana. E tentamos contemplar temas clássicos e reconhecidamente relevantes, como a intencionalidade e a liberdade.

Toda pesquisa de caráter empírico, por outro lado, implica restrições e simplificações, e isso vale para todas as ciências, e não apenas para aquelas que já alcançaram um grau elevado de aplicação de métodos matemáticos. Quaisquer modelos nas próprias ciências humanas - mesmo os mais eminentemente intencionais, nas ciências as mais refratárias à aplicação de métodos matemáticos -, em última instância, são simplificações para nos permitir algum entendimento do que acontece no mundo. Os riscos de retratar de forma inadequada um fenômeno estão em toda parte, mesmo quando não é questão de aplicar métodos matemáticos.

Por outro lado, a aplicação de ferramentas matemáticas, onde ela é possível sem desfigurar os fenômenos a serem estudados, constitui uma enorme vantagem no en- 
tendimento do que ocorre. O que pode então faltar - como faltou no passado para o próprio Newton - pode ser uma matemática mais poderosa.

Uma questão remanescente, mesmo que essas últimas considerações sejam aceitáveis, é se a filosofia da ciência ganha ou perde com as tentativas de pesquisas empíricas sobre os temas que são para ela importantes. Acreditamos que ela pode ganhar e a pequena contribuição que esse trabalho pretende dar deve ser compreendida na mesma linha de investigações epistemológicas como aquela de Thomas Kuhn que, apesar de suas reconhecidas limitações, enriqueceram enormemente as discussões na filosofia da ciência da segunda metade do século xx.e

Agradecimentos. Os autores agradecem o apoio do CNPq (edital universal 2007). Luiz Henrique Dutra, em particular, agradece o apoio dessa mesma agência no desenvolvimento de pesquisas (com bolsa de produtividade em pesquisa) que, nos últimos anos, permitiram o desenvolvimento de algumas das ideias aqui apresentadas e as publicações mencionadas que as veicularam.

\section{Luiz Henrique Dutra}

Professor associado do Departamento de Filosofia, Universidade Federal de Santa Catarina, Brasil.

Pesquisador do CNPq. lhdutra@cfh.ufsc.br

Cezar Mortari

Professor associado do Departamento de Filosofia, Universidade Federal de Santa Catarina, Brasil. cmortari@cfh.ufsc.br

Jerzy Brzozowski Doutorando do Programa de Pós-Graduação em Filosofia, Universidade Federal de Santa Catarina, Brasil. jerzyab@yahoo.com Thiagus Batista Mestre em Filosofia, Programa de Pós-Graduação em Filosofia, Universidade Federal de Santa Catarina, Brasil. TMBatista@mp.sc.gov.br 
Pragmática da investigaçÃo Gientífiga: uma abordagem nomológiga

\section{ABSTRACT}

This paper aims to discuss a typical event of scientific activity - namely, the publication of scientific papers - from the point of view of the pragmatics of scientific investigation combined with the perspective of Patrick Suppes regarding what would be a free choice. First, Suppes' idea of introducing a measure for freedom is presented. Secondly, an outline of the conception of pragmatics of scientific investigation is given. Finally, an interpretation of a trajectory of investigation in terms of Markov chains is presented.

KEYWords $\bullet$ Pragmatics of investigation. Markov chains. Free choice. Scientific papers. Patrick Suppes.

\section{REFERÊNGIAS BIBLIOGRÁFICAS}

CARTwright, N. The dappled world: a study of the boundaries of science. Cambridge: Cambridge University Press, 2003.

Dimitri, N.; Basili, M. \& Gilboa, I. (Ed.). Cognitive processes and economic behavior. New York: Routledge, 2003.

Dutra, L. H. A. Os modelos e a pragmática da investigação científica. Scientiae Studia, 3, 2, p. 205-32, 2005 .

Comportamento intencional e contextos sociais: uma abordagem nomológica. Abstracta, 2, 2, p. 102-28, 2006. . Pragmática da investigação científica. São Paulo: Loyola, 2008. An analysis of scientific behavior using first-order Markov chains. No prelo.

FraAssen, B. C. van. The scientific image. Oxford: Clarendon Press, 1980.

HerRnstein, R. J. The matching law: papers in psychology and economics. Cambridge: Harvard University Press, 1997 .

Hume, D. An enquiry concerning human understanding. Oxford: Clarendon Press, 1996.

Kunn, T. The structure of scientific revolutions. Chicago: University of Chicago Press, 1996.

Quine, W. V. O. Ontological relativity and other essays. New York: Columbia University Press, 1969.

Rachlin, H. Judgment, decision, and choice: a cognitive/behavioral synthesis. New York: W. H. Freeman and Company, 1989.

. Behavior and mind: the roots of modern psychology. New York: Oxford University Press, 1994.

Shannon, C. E. A mathematical theory of communication. The Bell Systems Technical Journal, 27, p. 379$423,623-56,1948$.

Skinner, B. F. Science and human behavior. New York: MacMillan, 1965. About behaviorism. New York: Vintage Books, 1976. Beyond freedom and dignity. New York, Bantam/Vintage, 1990 [1971]. Verbal behavior. Acton: Copley, 1992.

Suppes, P. Behavioristic foundations of utility. Economica, 29, 2, p. 186-202, 1961. Davidson's view on psychology as a science. In: Vermazen, B. \& Hintikka, M. B. (Ed.). Essays on Davidson: actions and events. Oxford: Clarendon Press, 1985. p. 183-94.

. Rationality, habits and freedom. In: Dimitri, N.; Basili, M. \& Gilboa, I. (Ed.). Cognitive processes and economic behavior. New York: Routledge, 2003. p. 137-67.

Tomé, T. \& Oliveira, M. J. Dinâmica estocástica e irreversibilidade. São Paulo: Editora da Universidade Federal de São Paulo, 2001.

Vermazen, B. \& Hintikka, M. B. (Ed.). Essays on Davidson: actions and events. Oxford: Clarendon Press, 1985 . 